\title{
Reproductive factors, intima media thickness and carotid plaques in a cross-sectional study of postmenopausal women enrolled in the population-based KORA F4 study
}

Doris Stöckl ${ }^{1,2^{*}}$, Annette Peters ${ }^{1}$, Barbara Thorand ${ }^{1}$, Margit Heier ${ }^{1,3}$, Wolfgang Koenig ${ }^{4}$, Jochen Seissler ${ }^{5}$, Joachim Thiery ${ }^{6}$, Wolfgang Rathmann ${ }^{7}$ and Christa Meisinger ${ }^{1,3}$

\begin{abstract}
Background: Reproductive events may affect the onset of chronic diseases. We examined the possible association between reproductive parameters and intima media thickness (IMT) or carotid plaques in the common carotid artery in a population-based sample.

Methods: This cross-sectional study analysed data of 800 postmenopausal women aged 50 to 81 years of the population-based KORA F4 study, conducted between 2006 and 2008 in Southern Germany. Reproductive parameters were obtained by standardised interviews.

Results: Age at menarche below 12 years compared to 12-15 years was significantly associated with carotid plaques (age-adjusted OR 2.23, 95\% Cl 1.13-4.43, p-value 0.018, multivariable adjusted 2.11, 1.05-4.26, 0.037), but not with IMT. Ever use of hormone replacement therapy was inversely associated with carotid plaques (age-adjusted $0.60,0.44-0.81, p=0.001$, multivariable-adjusted $0.62,0.45-0.86,0.003$ ) and IMT in the age-adjusted model (mean 0.89, $95 \% \mathrm{Cl} 0.88-0.90, \mathrm{p}=0.033$ ) but not in the multivariable-adjusted model (mean $0.89,95 \% \mathrm{Cl} 0.88-0.90, \mathrm{p}=0.075$ ). Parity, age at menopause, time since menopause, duration of fertile period, current use of hormone replacement therapy, ever use of oral contraceptives, hysterectomy, bilateral oophorectomy, hot flashes and depressive mood in relation to the menopausal transition were not associated with carotid plaques or IMT.
\end{abstract}

Conclusion: Our study showed, that there may be an independent association between the reproductive parameters age at menarche and ever use of hormone replacement therapy with carotid plaques in the common carotid artery, but not with IMT. Further research, especially in studies with prospective population-based study design, is necessary to assess in detail what events in women's life lead to increased IMT or CP.

Keywords: Intima media thickness, Atherosclerosis, Cardiovascular disease, Women, Reproductive factors, Gender studies

\section{Background}

The identification of risk factors or risk markers for prevention of cardiovascular disease (CVD) represents an important research area. Subclinical atherosclerosis, a risk factor for cardiovascular events, can be assessed noninvasively by ultrasonography of the carotid arteries by

\footnotetext{
* Correspondence: doris.stoeckl@helmholtz-muenchen.de

${ }^{1}$ Institute of Epidemiology II, Helmholtz Zentrum München, German Research Center for Environmental Health, Neuherberg, Germany

${ }^{2}$ Department of Obstetrics and Gynaecology, Campus Grosshadern, LudwigMaximilians-University, Munich, Germany

Full list of author information is available at the end of the article
}

assessing intima media thickness (IMT) and the presence of plaques $(\mathrm{CP})$. The presence and progression of IMT and $\mathrm{CP}$ are associated with the development of coronary artery disease events to some extend [1-4]. Yet, a recently published meta-analysis found $\mathrm{CP}$ to be more accurate than IMT in predicting these events [5].

CVD affects women nearly as often as men. In earlier adulthood, women are more protected, but after menopause the sex difference diminishes [6], suggesting an effect of female hormones with possible protection of the premenopausal hormonal status. So far, there is a 
lack of gender specific studies on CVD risk, treatment and prognosis.

Reproductive events during the life-span of women have been shown to be associated with chronic diseases. Lower age at menarche is associated with diabetes [7], CVD [8], metabolic syndrome [9] and mortality [8]. Parity was shown to be associated with CVD [10] and the metabolic syndrome [11,12]. The menopausal transition is associated with CVD [13] and hormone replacement therapy (HRT) in form of estrogen and progesterone application increases the risk of CVD [14]. But HRT has been reported to have an initially protective effect on the calcification of the coronary arteries [15].

There are only a few prior studies on whether reproductive factors are associated with IMT or $\mathrm{CP}$, which are markers for early atherosclerosis and appear before the onset of symptomatic CVD. A population-based study of 746 Finish women aged 45-74 showed that of all examined reproductive factors, only stillbirth was associated with an increased risk of atherosclerotic plaques [16]. This study has examined various reproductive factors, but for example age at menarche was not examined. Other studies have only examined selected reproductive factors and their association with IMT and so far there are only few population-based studies. Oophorectomy before natural menopause [17] and hot flashes, as a sign of the vasomotor symptoms during menopausal transition have been found to be associated with an increased IMT $[18,19]$, but other studies don't support this association [20]. Parity has been related to increased IMT [21] in younger [22] as well as in elderly women [23].

The aim of this study is to investigate whether there is an association between a variety of reproductive parameters and IMT and CP in the common carotid artery (CCA) in postmenopausal women from the general population.

\section{Methods \\ Subjects}

The KORA F4 (2006-2008) study is the 7-year follow-up study of the KORA S4 (1999-2001) study, a populationbased health survey performed in the city of Augsburg and their two surrounding counties in Southern Germany. The abbreviation KORA stands for Cooperative Health Research in the Region of Augsburg. The target population for the S4 baseline study consists of all German residents of the region aged 25 to 74 years. Of the randomly selected 6640 subjects, 4261 (64.2\%) participated in the S4 baseline study. The study design, sampling method and data collection have been described in detail elsewhere [24].

Of the 4261 participants in S4, 3080 took part in the F4 follow-up study. Participants were not invited for F4 if they were deceased $(n=176,4 \%)$, relocated outside the study region, were lost to follow-up $(n=206,5 \%)$ or had demanded deletion of their address data $(n=12,0.2 \%)$. Of the remaining 3867 eligible persons, the contact failed for 174, 218 were not able to participate in the study because they were too ill or had no time, and 395 denied participation in the follow-up. The final response rate was $79.6 \%$.

For the current analysis all postmenopausal women aged 50 to 81 years at follow-up $(\mathrm{n}=940)$ were included.

From this sample, we excluded 140 females for whom no or incomplete information on CP, carotid IMT or any of the covariables was available. Therefore, this analysis finally included 800 study participants. These 140 excluded women did not differ significantly regarding age, BMI and other main charactersistcs from the included 800 women.

The investigations were carried out in accordance with the Declaration of Helsinki, including written informed consent of all study participants. The study was approved by the Ethics Committee of the Bavarian Medical Association.

\section{Data collection}

Information on sociodemographic variables, smoking habits, physical activity level, medication use, reproductive parameters and alcohol consumption were gathered by trained medical staff during a standardized interview. Education was estimated by recording years of schooling completed. In addition, all study participants underwent a standardized medical examination. All measurement procedures have been described in detail elsewhere [24]. Anthropometric measurements were performed after subjects had removed their shoes, heavy clothing and belts. Body height was measured to the nearest $0.1 \mathrm{~cm}$ and weight to the nearest $0.1 \mathrm{~kg}$. BMI was calculated as weight $[\mathrm{kg}]$ divided by height ${ }^{2}\left[\mathrm{~m}^{2}\right]$. Waist circumference (WC) was measured at the level midway between the lower rib margin and the iliac crest. Actual hypertension was defined as blood pressure values greater than $140 / 90 \mathrm{mmHg}$ or the use of antihypertensive medication, given that the subjects were aware of being hypertensive. Individuals who participated in leisure time physical activity during summer and winter and were active for at least one hour per week in either season were classified as being physically active. Women who consumed more than $20 \mathrm{~g}$ alcohol per day were regarded as heavy alcohol drinkers. A fasting venous blood sample was obtained from all study participants while sitting. The parameters total cholesterol, triglycerides and fasting blood glucose were used for the analysis. Fasting blood glucose was analyzed using a hexokinase method (GLU Flex of Dade Behring, Germany), fasting triglycerides (TG) with the TGL Flex GPO-PAP assay of Dade Behring and the analysis of total cholesterol wase carried out using the analyzer Dimension RxL (Dade Behring, Germany).

\section{Assessment of reproductive parameters}

Reproductive parameters were obtained through personal interviews by trained medical staff in the KORA S4 and 
F4 surveys and have been described previously [25]. Most variables were obtained in both interviews and underwent rigorous quality assessment for internal validity. For this analysis mainly data of the KORA F4 study were used.

Women were classified postmenopausal at the absence of menstrual bleeding for 12 consecutive months, if they had bilateral oophorectomy (either alone or in combination with hysterectomy) and had hysterectomy without bilateral oophorectomy and were above 50 years (without reported menopause before hysterectomy). This was asked in the S4 and F4 interview. Age at menarche was defined as age at the first menstrual bleeding, assessed in full years. The question, which was asked only in the baseline S4 study was open-ended: "At what age did you have your first menstrual period (menarche)?" Women were asked in S4 and F4 to recall their number of pregnancies and live-born children, if they ever used oral contraceptives or HRT. Parity was defined as the number of reported deliveries. At the examination date in the F4 study, all subjects were asked to bring their current medication to the study center and the barcode of each medication was scanned. From these data the category current use of HRT was constructed. There was no further differentiation in the type of HRT, e.g. with or without progestin use. Ever use of oral contraception or HRT was assessed in the interviews. Furthermore the women were asked about the presence of two symptoms of the menopausal transition: hot flashes and depressive mood. Age at menopause was inquired in both surveys and is only available for 602 women. The high amount of missing values is due to the difficult assessment of this variable, because ongoing vaginal bleeding due to HRT and hysterectomy early in life without bilateral oophorectomy while still being premenopausal, make an age determination challenging and some women simply don't remember their age at menopause. From the variable age at menopause the variables time since menopause (current age minus age at menopause) in years and fertility duration (age at menopause minus age at menarche) in years are constructed.

\section{Vascular examination}

Ultrasound measurement of IMT was performed as described previously [26]. Briefly, CCAs were scanned in angles of $60^{\circ}-180^{\circ}$ (right CCA) and $210^{\circ}-300^{\circ}$ (left CCA) using a high resolution ultrasound system (Sonoline G50, Siemens Medical Solutions, Munich, Germany or Acuson X300, Siemens Medical Solutions, Munich, Germany). Optimal images of the far wall were recorded on DVD videotapes. Measurements of IMT were performed off-line over a length of $10 \mathrm{~mm}$ beginning at 0-5 $\mathrm{mm}$ of the dilatation of the distal CCA using an automated edge detection reading system (Prowin software, Medical Technologies International, USA) by one certified reader. The mean of the left and right CCA were used to calculate IMT.

Plaques were defined as a distinct area with either rising into the lumen or mineralization. CP assessment was performed from the DVD videotapes which were recorded for the IMT measurement. Therefore only plaques in the CCA were assessed. No further vessels were scanned for plaques.

\section{Statistical analyses}

Basic characteristics of the study population were analyzed for the whole sample and stratified for carotid plaques. For normally distributed variables the mean and standard deviation and for categorical variables percentages were calculated. Two models were fitted, the first one controlling for age, the second model uses a multivariable approach with age, BMI, education, family status, physical activity, smoking, alcohol consumption, fasting blood glucose levels, total cholesterol and triglycerides as potential confounder. For the selection of confounder a literature research was performed, which showed that age, BMI, social status (education and family status were considered in our study to represent social status), physical activity, alcohol consumption and smoking were included as confounder in comparable studies $[1,16,27]$. Generalized linear models were used for the analysis of IMT and logistic regression analyses for CP.

Significance tests were two-tailed and p-values less than 0.05 were considered statistically significant. All analyses were performed using SAS (version 9.3, SAS Institute Inc, Cary, NC, USA).

\section{Results}

This study comprises 800 postmenopausal women aged 50 to 81 years. Basic characteristics of the whole study sample and according to the presence or absence of CP in the CCA are presented in Table 1. Women with CP were older and more likely to suffer from hypertension or diabetes. They were less likely to be heavy alcohol drinkers and were less physically active. Women without $\mathrm{CP}$ were more likely to have a history of oral contraceptive or HRT use.

The mean IMT of all women included in this analysis was $0.895 \mathrm{~mm}$ with a standard deviation of 0.124 . Table 2 presents the associations between the examined reproductive parameters and IMT. Ever use of HRT, but not current use, was associated with IMT in the age-adjusted model (mean 0.89, 95\% CI 0.88-0.90, p-value 0.033). After further adjustment for additional risk factors statistical significance was lost. There was no significant interaction between current use of HT and time since menopause (p-value 0.711). Parity, age at menopause, time since menopause, duration of fertile period, current use of hormone replacement therapy, ever use of oral contraceptives, 
Table 1 Selected characteristics of the study population for the whole sample and stratified for carotid plaques in the common carotid artery

\begin{tabular}{|c|c|c|c|c|}
\hline & Whole study population & No plaque & Plaque & p-values \\
\hline$n$ & 800 & 498 & 302 & \\
\hline Age (years) & $64.2(8.2)$ & $62.0(7.6)$ & $67.9(8.0)$ & $<0.0001$ \\
\hline IMT (mm) & $0.895(0.124)$ & $0.856(0.109)$ & $0.961(0.119)$ & $<0.0001$ \\
\hline Waist circumference $(\mathrm{cm})$ & $91.4(12.5)$ & $90.7(12.9)$ & $92.5(11.8)$ & 0.051 \\
\hline BMI $\left(\mathrm{kg} / \mathrm{m}^{2}\right)$ & $28.4(5.1)$ & $28.2(5.2)$ & $28.7(4.9)$ & 0.143 \\
\hline BMl at age 25 years $\left(\mathrm{kg} / \mathrm{m}^{2}\right)$ & $22.5(3.3)$ & $22.4(3.4)$ & $22.7(3.2)$ & 0.300 \\
\hline Family status (\%) & & & & 0.075 \\
\hline Single & 5.3 & 4.8 & 6.5 & \\
\hline Married & 66.8 & 69.4 & 61.6 & \\
\hline Divorced or widowed & 28.0 & 25.8 & 32.0 & \\
\hline Education $<10$ years (\%) & 62.3 & 57.2 & 70.1 & 0.0003 \\
\hline Systolic BP (mmHg) & $121.6(18.1)$ & $120.6(16.6)$ & $125.0(19.8)$ & 0.001 \\
\hline Diastolic BP (mmHg) & $73.6(9.2)$ & $74.5(8.8)$ & $72.5(9.7)$ & 0.003 \\
\hline History of diabetes $(\%)^{1}$ & 13.2 & 11.2 & 16.7 & 0.029 \\
\hline Actual hypertension $(\%)^{2}$ & 44.8 & 40.7 & 55.8 & $<0.0001$ \\
\hline Current use of antihypertensive medication (\%) & 41.1 & 33.5 & 53.7 & $<0.0001$ \\
\hline Total cholesterol (mg/dl) & $230.6(38.5)$ & $62.6(14.6)$ & $61.0(14.8)$ & 0.951 \\
\hline Fasting glucose (mg/dl) & $98.7(17.3)$ & $97.5(15.3)$ & $100.8(20.0)$ & 0.010 \\
\hline Triglycerides (mg/dl) & $121.3(73.9)$ & $119.0(77.4)$ & $125.2(66.8)$ & 0.251 \\
\hline Alcohol > 20 g/day (\%) & 16.0 & 16.1 & 15.0 & 0.079 \\
\hline Current smoking (\%) & 10.9 & 11.2 & 10.9 & 0.844 \\
\hline Physically active (\%) & 56.0 & 60.1 & 48.0 & 0.001 \\
\hline Menarche (years) & $13.6(1.7)$ & $13.6(1.6)$ & $13.8(1.8)$ & 0.104 \\
\hline Parity (\%) & & & & 0.195 \\
\hline 0 & 11.8 & 10.3 & 14.6 & \\
\hline $1-2$ & 48.1 & 49.8 & 44.9 & \\
\hline$>2$ & 40.2 & 39.9 & 40.5 & \\
\hline Age at menopause (years) ${ }^{3}$ & $49.0(5.0)$ & $48.7(5.1)$ & $49.3(4.8)$ & 0.143 \\
\hline Time since menopause (years) ${ }^{3}$ & $15.8(9.0)$ & $13.8(8.6)$ & $18.9(8.7)$ & $<0.0001$ \\
\hline Duration of Fertility (years) ${ }^{3}$ & $35.3(5.1)$ & $35.1(5.2)$ & $35.5(5.0)$ & 0.322 \\
\hline Current HRT (\%) & 14.4 & 16.9 & 10.5 & 0.010 \\
\hline Ever HRT (\%) & 59.0 & 64.0 & 50.3 & $<0.0001$ \\
\hline Ever OC (\%) & 61.6 & 66.7 & 54.8 & 0.0005 \\
\hline Hysterectomy $(\%)$ & 33.8 & 34.7 & 32.0 & 0.286 \\
\hline Bilateral oophorectomy (\%) & 6.8 & 7.0 & 6.5 & 0.687 \\
\hline Hot flashes (\%) & 43.2 & 48.3 & 34.7 & $<0.0001$ \\
\hline Depressive mood (\%) & 37.1 & 35.7 & 37.8 & 0.695 \\
\hline
\end{tabular}

Data presented as mean (standard deviation) or percentage respectively.

Abbreviations: BMI: Body Mass Index, BP: Blood pressure, HRT: Hormone replacement therapy, OC: oral contraceptives.

$\mathrm{p}$-values are presented for the difference of present and absent plaques.

${ }^{1}$ missing information for 13 women.

2 actual hypertension was defined as current use of blood pressure lowering medication or a blood pressure $\geq 140 / 90 \mathrm{mmHg}$, given that the subjects were aware of being hypertensive.

${ }^{3} \mathrm{n}=602$, due to missing values of age at menopause. 
Table 2 Intima media thickness $(\mathrm{mm})$ and reproductive parameters in 800 postmenopausal women from the KORA F4 study

\begin{tabular}{|c|c|c|c|c|c|c|}
\hline \multirow{3}{*}{ Menarche } & \multicolumn{3}{|c|}{ Age-adjusted } & \multicolumn{3}{|c|}{ Multivariable-adjusted } \\
\hline & Mean & $95 \% \mathrm{Cl}$ & p-value & Mean & $95 \% \mathrm{Cl}$ & $\mathrm{p}$-value \\
\hline & & & 0.701 & & & 0.873 \\
\hline$<12$ years & 0.906 & $0.879-0.933$ & & 0.902 & $0.875-0.929$ & \\
\hline $12-15$ years & 0.895 & $0.886-0.903$ & & 0.894 & $0.886-0.903$ & \\
\hline$>15$ years & 0.892 & $0.872-0.914$ & & 0.896 & $0.875-0.917$ & \\
\hline Parity & & & 0.114 & & & 0.407 \\
\hline 0 & 0.876 & $0.854-0.898$ & & 0.883 & $0.860-0.905$ & \\
\hline $1-2$ & 0.895 & $0.884-0.906$ & & 0.895 & $0.884-0.906$ & \\
\hline$>2$ & 0.902 & $0.890-0.914$ & & 0.900 & $0.888-0.912$ & \\
\hline Age at menopause ${ }^{1}$ & & & 0.766 & & & 0.590 \\
\hline$\geq 50$ years & 0.903 & $0.890-0.915$ & & 0.904 & $0.891-0.916$ & \\
\hline$<50$ years & 0.900 & $0.887-0.913$ & & 0.899 & $0.886-0.912$ & \\
\hline Time since menopause ${ }^{1}$ & & & 0.136 & & & 0.079 \\
\hline$>15$ years & 0.891 & $0.875-0.907$ & & 0.889 & $0.873-0.905$ & \\
\hline$\leq 15$ years & 0.911 & $0.895-0.928$ & & 0.913 & $0.897-0.929$ & \\
\hline Duration of fertility ${ }^{1}$ & & & 0.645 & & & 0.683 \\
\hline$>35.0$ & 0.903 & $0.891-0.913$ & & 0.903 & $0.891-0.915$ & \\
\hline$\leq 35.0$ & 0.899 & $0.886-0.909$ & & 0.899 & $0.886-0.912$ & \\
\hline Current use of HRT & & & 0.817 & & & 0.711 \\
\hline Yes & 0.893 & $0.873-0.913$ & & 0.899 & $0.879-0.919$ & \\
\hline No & 0.896 & $0.887-0.904$ & & 0.895 & $0.887-0.903$ & \\
\hline Ever use of HRT & & & 0.033 & & & 0.075 \\
\hline Yes & 0.888 & $0.878-0.898$ & & 0.890 & $0.880-0.900$ & \\
\hline No & 0.905 & $0.893-0.917$ & & 0.902 & $0.891-0.914$ & \\
\hline Ever use of $O C$ & & & 0.767 & & & 0.394 \\
\hline Yes & 0.896 & $0.886-0.906$ & & 0.898 & $0.888-0.908$ & \\
\hline No & 0.894 & $0.880-0.907$ & & 0.891 & $0.878-0.904$ & \\
\hline Hysterectomy & & & 0.370 & & & 0.277 \\
\hline Yes & 0.890 & $0.877-0.903$ & & 0.888 & $0.875-0.901$ & \\
\hline No & 0.898 & $0.888-0.907$ & & 0.899 & $0.890-0.908$ & \\
\hline Bilateral oophorectomy & & & 0.775 & & & 0.614 \\
\hline Yes & 0.891 & $0.862-0.920$ & & 0.888 & $0.859-0.917$ & \\
\hline No & 0.896 & $0.888-0.903$ & & 0.896 & $0.888-0.904$ & \\
\hline Hot flashes & & & 0.684 & & & 0.452 \\
\hline Yes & 0.893 & $0.881-0.905$ & & 0.892 & $0.880-0.904$ & \\
\hline No & 0.897 & $0.886-0.907$ & & 0.898 & $0.888-0.908$ & \\
\hline Depressive mood & & & 0.753 & & & 0.989 \\
\hline Yes & 0.897 & 0.884-0.909 & & 0.895 & $0.883-0.906$ & \\
\hline No & 0.894 & $0.885-0.904$ & & 0.895 & $0.886-0.905$ & \\
\hline
\end{tabular}

Abbreviations: HRT: Hormone replacement therapy, OC: oral contraceptives.

Generalized linear models.

Estimated means of IMT are presented.

Multivariable-adjusted: Age, BMI, education, family status, physical activity, smoking, alcohol consumption, total cholesterol, triglycerides and fasting blood glucose.

${ }^{1} n=602$, due to missing values of age at menopause. 
hysterectomy, bilateral oophorectomy, hot flashes and depressive mood in relation to the menopausal transition were not associated with IMT.

Table 3 displays the association between the reproductive parameters and $\mathrm{CP}$ in the CCA, assessed by logistic regression analysis. Ever use of HRT, but not current use, was significantly inversely associated with CP (ageadjusted: OR $0.60,95 \%$ CI $0.44-0.81$, and multivariableadjusted: OR $0.62,95 \% \mathrm{CI} 0.45-0.86$ ) and lower age at menarche was associated with $\mathrm{CP}$ (below 12 years, compared to 12-15years) (age-adjusted: OR 2.23, 95\% CI 1.13-4.43, multivariable-adjusted: OR $2.11,95 \%$ CI 1.05-4.26). All other examined reproductive parameters showed no significant association with $\mathrm{CP}$.

\section{Discussion}

The present cross-sectional study shows that only a few reproductive parameters are associated with IMT and CP in the CCA, both early markers of atherosclerosis. There was an age-adjusted association of ever use of HRT with decreased IMT and reduced presence of CP, however, statistical significance remained only for $\mathrm{CP}$ after multivariable adjustment. An age at menarche below 12 years was associated with increased presence of $\mathrm{CP}$, but not IMT. All other examined reproductive factors did not show an association, neither with CP nor IMT.

The findings in this study support the results from other studies in which early age at menarche has been shown to be associated with premature CVD [8], cardiovascular risk factors like metabolic syndrome [9], diabetes [7] as well as peripheral arterial disease (PAD) [28]. The underlying reasons for these associations are not completely understood. Earlier onset of menarche could be due to obesity in childhood. It has been shown that obese children who stayed obese in adolescence and young adulthood had an increased risk of carotid-artery atherosclerosis, as well as hypertension, dyslipidemia and type 2 diabetes. This effect could not be shown in obese children who were normal weight in adulthood. Their risk was comparable to never obese individuals [29]. Thus, it might be assumed that obesity has an effect on the association between early age at menarche and early signs of atherosclerosis, such as IMT or CP. However, in the present study, earlier age at menarche was independently of BMI associated with the presence of CP. This finding needs to be confirmed or refuted in further large, particularly prospective population-based studies. Another pathway for the association of age at menarche with $\mathrm{CP}$ might be due to genetic traits. Recent genome-wide association studies showed obesity loci to be associated with age at menarche, suggesting complex genetic interrelationships [30].

In the present study ever use of HRT was associated with a lower risk of $\mathrm{CP}$ in the CCA, even after multivariable adjustment, while current use of HRT was not associated with CP. A cross-sectional study in 538 postmenopausal women in France, Belgium and the Netherlands showed that ever users of HRT had smaller and thinner carotid artery walls than nonusers with a lower rate of progression of subclinical atherosclerosis [31]. These findings are in partial contrast to findings from large observational studies like the Nurses' Health study or the randomized double-blinded Women's Health Initiative (WHI) [14,15]. Differences between observational studies and randomized trials have been argued to be due to the selection of women. It is known that women who chose to take HRT compared to women who did not, differ in certain characteristics like education, social status, and the prevalence of chronic diseases in observational epidemiologic studies [31]. The WHI showed that users of HRT have less calcification than nonusers, but they state that estrogen has complex biologic effects and may influence the risk for cardiovascular events and other outcomes through multiple pathways [15]. Recently published results show that there was no decreased risk of $\mathrm{CHD}$ in subgroups of women, e.g. who started HRT within 10 years after menopause. But subgroups were small [14]. We tried to adjust for all possible confounders, but residual confounding cannot be entirely excluded. Therefore our finding of an association between ever use of HRT and CP needs to be interpreted carefully. Hot flashes during the menopausal transition have been associated with increased IMT in some studies $[18,19]$, but other studies did not see this association [20,32]. The reasons for these conflicting results may be due to different study designs (e.g. assessment of hot flashes, inclusion and exclusion criteria) and differences in the study sample (e.g. age, position in the menopausal transition, cardiovascular risk factors). The association of hot flashes with CP has to our knowledge not been described before.

Premenopausal hormonal influence is expected to be protective of CVD. In early adulthood women are more protected than men, but after menopause this sex difference diminishes. Reproductive factors which occur over the life span of women do influence plasma levels of female hormones. This effect is well observed during pregnancy. Compared to non-pregnant women there are marked differences in the hormone levels with metabolic and functional changes. Cardiovascular regulations have been shown to change early in pregnancy, persist postpartum and seem to be enhanced during subsequent pregnancy [33]. The authors speculated that the changes during pregnancy might lower cardiovascular risk in later life. The findings in this study, where no associations between parity, and duration of fertility and IMT were found, are in contrast to other studies [21-23]. Wolff et al showed in another German population-based study (SHIP study) that nulliparity and a higher number of children were 
Table 3 Carotid plaques in the common carotid artery and reproductive parameters in 800 postmenopausal women, the KORA F4 study

\begin{tabular}{|c|c|c|c|c|c|c|}
\hline & \multicolumn{3}{|c|}{ Age-adjusted } & \multicolumn{3}{|c|}{ Multivariable-adjusted } \\
\hline & OR & $95 \% \mathrm{Cl}$ & p-value & OR & $95 \% \mathrm{Cl}$ & p-value \\
\hline \multicolumn{7}{|l|}{ Menarche } \\
\hline$<12$ years & 2.23 & $1.13-4.43$ & 0.018 & 2.11 & $1.05-4.26$ & 0.037 \\
\hline \multicolumn{7}{|c|}{$12-15$ years $^{* *}$} \\
\hline$>15$ years & 1.22 & $0.77-1.92$ & 0.290 & 1.25 & $0.79-1.99$ & 0.436 \\
\hline \multicolumn{7}{|l|}{ Parity } \\
\hline 0 & 1.37 & $0.83-2.26$ & 0.195 & 1.41 & $0.83-2.38$ & 0.186 \\
\hline $1-2$ & 1.01 & $0.73-1.41$ & 0.397 & 1.02 & $0.73-1.42$ & 0.383 \\
\hline
\end{tabular}

$>2^{* *}$

Age at menopause ${ }^{1}$

$\geq 50$ years

$0.66-1.33$

0.714

1.00

$0.70-1.45$

0.962

$<50$ years**

Time since menopause ${ }^{1}$

$>15$ years

$\leq 15$ years**

Duration of fertility ${ }^{1}$

$>35.0$ years

$\leq 35.0$ years ${ }^{* *}$

\section{Current use of HRT}

Yes

$\mathrm{No}^{* *}$

Ever use of HRT

Yes

$\mathrm{No}^{* *}$

Ever use of $\mathrm{OC}$

Yes

$\mathrm{No}^{* *}$

Hysterectomy

Yes

$\mathrm{No}^{* *}$

Bilateral oophorectomy

Yes

$\mathrm{No}^{* *}$

Hot flashes

Yes

$\mathrm{No}^{* *}$

\section{Depressed mood}

Yes

$\mathrm{No}^{* *}$

Logistic regression analyses.

Abbreviations: HRT: Hormone replacement therapy, OC: oral contraceptives

**reference group.

Multivariable-adjusted: Age, BMI, education, family status, physical activity, smoking, alcohol consumption, total cholesterol, triglycerides and fasting blood glucose.

${ }^{1} n=602$, due to missing values of age at menopause. 
associated with increased IMT [21]. They speculated that this association was partially mediated through conventional risk factors and socioeconomic determinants.

Genome-wide association studies have recently found no evidence that SNP's associated with coronary artery disease are associated with carotid IMT and therefore suggested that genetic associations are not acting via early vessel remodeling or early atherosclerosis [34].

IMT is a less reliable marker for early atherosclerosis than CP. IMT measurements are widely used in clinical practice to assess early atherosclerosis due to its noninvasive technique. But IMT without presence of $\mathrm{CP}$ represents mainly hypertensive medial hypertrophy and has a lower sensitivity to predict cardiovascular events [5]. A recent meta-analysis has shown that CP, compared with carotid IMT, more accurately predicts coronary artery disease events, like myocardial infarction [5]. The study showed that the absence of $\mathrm{CP}$ provides greater assurance with 10-year myocardial infarction event rates of $4.0 \%$ (95\% CI 3.6-4.7\%) [5].

The advantage of our study is the population-based design. The study sample was drawn randomly from the general population. Another strength is the collection of the data by experienced examiners according to standardized protocols. The sonographers did not know about the cardiovascular history of the subjects and measurements underwent rigorous quality control. Multiple reproductive factors have been assessed. Furthermore this study uses mean IMT values, which are better reproducible and less susceptible to outliers compared to maximal carotid IMT measurements which reflect more advanced stages with focal thickening [5]. Limitations are the crosssectional design; therefore cause and effect relationships cannot be stated. Screening for CP was only performed in the CCA during the measurement of IMT. This is a severe limitation for the results of our study, because no further vessels were screened for the prevalence of plaques, a procedure which has been recommended by Inaba et. al.: Carotid IMT assessment should always be supplemented by a thorough scan of the extra cranial carotid arteries for $\mathrm{CP}$ assessment to increase the diagnostic performance of carotid ultrasound [5]. Nevertheless we think that the results of our study are interesting and worth to be presented despite the lack of systematic plaque assessment because there are very few studies published who examined the association of reproductive parameters and CP. Another limitation of the study is that information on CVD events was not yet available for the analysis. Furthermore, some reproductive variables were categorized rather broad, like hot flashes. In the KORA F4 study the women were only asked if they currently suffer from hot flashes, without asking for the duration or severity. The same applies to current use or past use of HRT. The categories were yes/no without differentiation on application forms, dosages and formulas. A recall bias cannot be ruled out due to the assessment of reproductive variables in the interview.

\section{Conclusion}

Our study showed a significantly positive association of early menarche with CP in the common carotid artery and a significant inverse association of ever use of hormone replacement therapy and $\mathrm{CP}$. There was no independent association between any of the investigated reproductive parameters and IMT. The findings of this study are explorative and possibly due to chance and need to be proven in further population-based studies with a bigger sample size. Further research, especially in studies with prospective population-based study designs, is necessary to assess in detail what events in women's life lead to increased IMT or CP.

\section{Abbreviations}

BMI: Body mass index; BP: Blood pressure; CCA: Common carotid artery; CP: Carotid plaques; CVD: Cardiovascular disease; HRT: Hormone replacement therapy; IMT: Intima media thickness; OC: Oral contraceptives.

\section{Competing interest}

The authors declare that they have no competing interest.

\section{Authors' contribution}

DS planned the study, performed the data analysis and wrote the manuscript. CM contributed to the acquisition of data, planning of the study, the performance of the data analysis and reviewed and edited the manuscript. BT, AP, JT, WK, JS, WR and MH contributed to the acquisition of data and reviewed and edited the manuscript. All authors have viewed and approved the final version of the manuscript.

\section{Acknowledgement}

The KORA research platform (KORA, Cooperative Research in the Region of Augsburg) was initiated and financed by the Helmholtz Zentrum München, German Research Center for Environmental Health $(\mathrm{GmbH})$, which is funded by the German Federal Ministry of Education, Science, Research and Technology and by the State of Bavaria. The funders had no role in study design, data collection and analysis, decision to publish, or preparation of the manuscript. We thank all the study participants, all members of staff of the Institute of Epidemiology $\mid \mathrm{l}$ and the field staff in Augsburg who planned and conducted the study.

Measurement of IMT was funded by a grant of the Karl-Wilder-Foundation (JS).

\section{Author details}

${ }^{1}$ Institute of Epidemiology II, Helmholtz Zentrum München, German Research Center for Environmental Health, Neuherberg, Germany. 2Department of Obstetrics and Gynaecology, Campus Grosshadern, Ludwig-Maximilians-University, Munich, Germany. ${ }^{3}$ Central Hospital of Augsburg, MONICA/KORA Myocardial Infarction Registry, Augsburg, Germany. ${ }^{4}$ Department of Internal Medicine II - Cardiology, University of Ulm Medical Center, Ulm, Germany. ${ }^{5}$ Medizinische Klinik und Poliklinik IV, Diabetes Zentrum Campus Innenstadt, Klinikum der Ludwig-Maximilians-Universität, München and Clinical Cooperation Group Diabetes, Ludwig-Maximilians-Universität München and Helmholtz Zentrum München, Munich, Germany. ${ }^{6}$ Institute of Laboratory Medicine, Clinical Chemistry and Molecular Diagnostics, University of Leipzig, Leipzig, Germany. ${ }^{7}$ Institute of Biometrics and Epidemiology, German Diabetes Center, Leibniz Center for Diabetes Research at Heinrich Heine University, Düsseldorf, Germany.

Received: 12 August 2013 Accepted: 18 January 2014 Published: 24 January 2014 


\section{References}

1. Lamina C, Meisinger C, Heid IM, Lowel H, Rantner B, Koenig W, Kronenberg F: Association of ankle-brachial index and plaques in the carotid and femoral arteries with cardiovascular events and total mortality in a populationbased study with 13 years of follow-up. Eur Heart J 2006, 27:2580-2587.

2. Lorenz MW, Polak JF, Kavousi M, Mathiesen EB, Volzke H, Tuomainen TP Sander D, Plichart M, Catapano AL, Robertson CM, et al: Carotid intima-media thickness progression to predict cardiovascular events in the general population (the PROG-IMT collaborative project): a meta-analysis of individual participant data. Lancet 2012, 379:2053-2062.

3. Polak JF, Szklo M, Kronmal RA, Burke GL, Shea S, Zavodni AE, O'Leary DH: The value of carotid artery plaque and intima-media thickness for incident cardiovascular disease: the multi-ethnic study of atherosclerosis. J Am Heart Assoc 2013, 2:e000087.

4. Polak JF, Pencina MJ, Pencina KM, O'Donnell CJ, Wolf PA, D'Agostino RB Sr: Carotid-wall intima-media thickness and cardiovascular events. N Engl J Med 2011, 365:213-221.

5. Inaba Y, Chen JA, Bergmann SR: Carotid plaque, compared with carotid intima-media thickness, more accurately predicts coronary artery disease events: a meta-analysis. Atherosclerosis 2012, 220:128-133.

6. Gerhard M, Baum P, Raby KE: Peripheral arterial-vascular disease in women: prevalence, prognosis, and treatment. Cardiology 1995, 86:349-355.

7. Stöckl D, Döring A, Peters A, Thorand B, Heier M, Huth C, Stöckl H, Rathmann W, Kowall B, Meisinger C: Age at menarche is associated with prediabetes and diabetes in women (aged 32-81 years) from the general population: the KORA F4 Study. Diabetologia 2012, 55:681-688

8. Lakshman R, Forouhi NG, Sharp SJ, Luben R, Bingham SA, Khaw KT, Wareham NJ, Ong KK: Early age at menarche associated with cardiovascular disease and mortality. J Clin Endocrinol Metab 2009, 94:4953-4960.

9. Stöckl D, Meisinger C, Peters A, Thorand B, Huth C, Heier M, Rathmann W, Kowall B, Stöckl H, Döring A: Age at menarche and its association with the metabolic syndrome and its components: results from the KORA F4 study. PLoS One 2011, 6:e26076.

10. Parikh NI, Cnattingius S, Dickman PW, Mittleman MA, Ludvigsson JF, Ingelsson E: Parity and risk of later-life maternal cardiovascular disease. Am Heart J 2010, 159:215-221. e216.

11. Cohen A, Pieper CF, Brown AJ, Bastian LA: Number of children and risk of metabolic syndrome in women. J Womens Health (Larchmt) 2006, 15:763-773

12. Gunderson EP, Jacobs DR Jr, Chiang V, Lewis CE, Tsai A, Quesenberry CP Jr, Sidney S: Childbearing is associated with higher incidence of the metabolic syndrome among women of reproductive age controlling for measurements before pregnancy: the CARDIA study. Am J Obstet Gynecol 2009, 201:177. e171-179.

13. Kannel WB, Hjortland MC, McNamara PM, Gordon T: Menopause and risk of cardiovascular disease: the Framingham study. Ann Intern Med 1976, 85(4):447-52.

14. Toh S, Hernandez-Diaz S, Logan R, Rossouw JE, Hernan MA: Coronary heart disease in postmenopausal recipients of estrogen plus progestin therapy: does the increased risk ever disappear? A randomized trial. Ann Intern Med 2010, 152:211-217.

15. Manson JE, Allison MA, Rossouw JE, Carr JJ, Langer RD, Hsia J, Kuller LH, Cochrane BB, Hunt JR, Ludlam SE, et al: Estrogen therapy and coronary-artery calcification. N Engl J Med 2007, 356:2591-2602.

16. Kharazmi E, Moilanen L, Fallah M, Kaaja R, Kattainen A, Kahonen M, Jula A, Kesaniemi A, Luoto R: Reproductive history and carotid intima-media thickness. Acta Obstet Gynecol Scand 2007, 86:995-1002.

17. Ozkaya E, Cakir E, Okuyan E, Cakir C, Ustun G, Kucukozkan T: Comparison of the effects of surgical and natural menopause on carotid intima media thickness, osteoporosis, and homocysteine levels. Menopause 2011, 18:73-76.

18. Thurston RC, Sutton-Tyrrell K, Everson-Rose SA, Hess R, Powell LH, Matthews KA: Hot flashes and carotid intima media thickness among midlife women. Menopause 2011, 18:352-358.

19. Ozkaya E, Cakir E, Kara F, Okuyan E, Cakir C, Ustun G, Kucukozkan T: Impact of hot flashes and night sweats on carotid intima-media thickness and bone mineral density among postmenopausal women. Int J Gynaecol Obstet 2011, 113:235-238.

20. Bechlioulis A, Kalantaridou SN, Naka KK, Chatzikyriakidou A, Calis KA, Makrigiannakis A, Papanikolaou O, Kaponis A, Katsouras C, Georgiou I, et al: Endothelial function, but not carotid intima-media thickness, is affected early in menopause and is associated with severity of hot flushes. $J$ Clin Endocrinol Metab 2010, 95:1199-1206.

21. Wolff B, Volzke H, Robinson D, Schwahn C, Ludemann J, Kessler C, John U, Felix SB: Relation of parity with common carotid intima-media thickness among women of the study of health in Pomerania. Stroke 2005, 36:938-943.

22. Skilton MR, Bonnet F, Begg LM, Juonala M, Kahonen M, Lehtimaki T, Viikari JS, Raitakari OT: Childbearing, child-rearing, cardiovascular risk factors, and progression of carotid intima-media thickness: the Cardiovascular Risk in Young Finns study. Stroke 2010, 41:1332-1337.

23. Humphries KH, Westendorp IC, Bots ML, Spinelli JJ, Carere RG, Hofman A, Witteman JC: Parity and carotid artery atherosclerosis in elderly women: the Rotterdam study. Stroke 2001, 32:2259-2264.

24. Meisinger C, Thorand B, Schneider A, Stieber J, Doring A, Lowel H: Sex differences in risk factors for incident type 2 diabetes mellitus: the MONICA Augsburg cohort study. Arch Intern Med 2002, 162:82-89.

25. Stöckl D, Döring A, Thorand B, Heier M, Peters A, Lamina C, Kronenberg F, Meisinger $C$ : Reproductive factors and its association with peripheral arterial disease in women aged 52-81 years: the KORA F4 study. Atherosclerosis 2013, 228:224-229.

26. Kowall B, Ebert N, Then C, Thiery J, Koenig W, Meisinger C, Rathmann W, Seissler J: Associations between blood glucose and carotid intima-media thickness disappear after adjustment for shared risk factors: the KORA F4 study. PloS One 2012, 7:e52590.

27. Yeh ST, Morton DJ, Barrett-Connor E: Lower extremity arterial disease in older women: the Rancho Bernardo study. J Womens Health Gend Based Med 2000, 9:373-380.

28. Hirsch AT, Allison MA, Gomes AS, Corriere MA, Duval S, Ershow AG, Hiatt WR, Karas RH, Lovell MB, McDermott MM, et al: A call to action: women and peripheral artery disease: a scientific statement from the American Heart Association. Circulation 2012, 125:1449-1472.

29. Juonala M, Magnussen CG, Berenson GS, Venn A, Burns TL, Sabin MA, Srinivasan SR, Daniels SR, Davis PH, Chen W, et al: Childhood adiposity, adult adiposity, and cardiovascular risk factors. N Engl J Med 2011, 365:1876-1885.

30. Fernandez-Rhodes L, Demerath EW, Cousminer DL, Tao R, Dreyfus JG, Esko T, Smith AV, Gudnason V, Harris TB, Launer L, et al: Association of adiposity genetic variants with menarche timing in 92,105 women of European descent. Am J Epidemio/ 2013, 178:451-460.

31. Gompel A, Boutouyrie P, Joannides R, Christin-Maitre S, Kearny-Schwartz A, Kunz K, Laurent S, Boivin JM, Pannier B, Pornel B, et al: Association of menopause and hormone replacement therapy with large artery remodeling. Fertil Steril 2011, 96:1445-1450.

32. Wolff EF, He Y, Black DM, Brinton EA, Budoff MJ, Cedars MI, Hodis HN, Lobo RA, Manson JE, Merriam GR, et al: Self-reported menopausal symptoms, coronary artery calcification, and carotid intima-media thickness in recently menopausal women screened for the Kronos early estrogen prevention study (KEEPS). Fertil Steril 2013, 99:1385-1391.

33. Clapp JF 3rd, Capeless E: Cardiovascular function before, during, and after the first and subsequent pregnancies. Am J Cardiol 1997, 80:1469-1473.

34. Conde L, Bevan S, Sitzer M, Klopp N, Illig T, Thiery J, Seissler J, Baumert J, Raitakari $\mathrm{O}$, Kahonen $\mathrm{M}$, et al: Novel associations for coronary artery disease derived from genome wide association studies are not associated with increased carotid intima-media thickness, suggesting they do not act via early atherosclerosis or vessel remodeling. Atherosclerosis 2011, 219:684-689.

doi:10.1186/1472-6874-14-17

Cite this article as: Stöckl et al:: Reproductive factors, intima media thickness and carotid plaques in a cross-sectional study of postmenopausal women enrolled in the population-based KORA F4 study. BMC Women's Health 2014 14:17. 